Prof. M. A. NAIMARK, Moscow State University

\title{
NORMED RINGS
}

A systematic compendium of the ideas, methods and results of the theory of Banach algebras.

Translated from the first Russian edition by Leo F. Boron

(Pennsylvania State University)

A monumental work for the specialist, but just as well one of the very small number of books devoted to this branch of mathematics which is also intended for the student!

\section{Contents}

1. Basic ideas from topology and functional analysis - 2. Fundamental concepts and propositions in the theory of normed rings - 3 . Commutative normed rings - 4. Representations of symmetric rings - 5. Some special rings - 6. Group rings

- 7. Rings of operators in Hilbert space - 8. Decomposition of a ring of operators into irreducible rings.

$1960 x v i+542$ pages + index $\$ 12$. , cloth $\$ 13$. "Is is indeed useful to have this fine book available in English. You have performed a valuable service for students and research workers in the field of functional analysis."

(From a letter from Angus E. TAYLOR, Chairman Math. Dept., Univ. of California)

Order through your local bookseller or direct from

P. Noordhoff Ltd - P.O.B. 39 - Groningen, The Netherlands

\section{COMPOSITIO MATHEMATICA}

This journal, with its editorial board of international character, ranks high among the mathematical journals of the world. Its aims are to further the development of mathematics and international co-operation. The services of the following distinguished mathematicians have been secured:

P. Alexandroff, G. Ancochea, E. Artin, R. Baer, S. Bernstein, E. Bompiani, L. E. J. Brouwer, H. Cartan, E. Cech, J. G. van der Corput, Th. de Donder, S. Eilenberg, H. Freudenthal, R. Garnier, J. C. H. Gerretsen, A. Heyting, Einar Hille, W. V. D. Hodge, H. Hopf, S. T. Hu, G. Julia, E. Kamke, A. Khintchine, S. C. Kleene, H. D. Kloosterman, J. F. Koksma, S. Lefschetz, P. Lévy, S. Maclane, P. Montel, M. Morse, J. von Neumann, N. E. Norlund, A. Ostrowski, M. Picone, W. Saxer, J. A. Schouten, F. Severi, W. Sierpinski, S. Stoïlow, G. Szegö, Ch. J. de la Vallée Poussin.

The journal appears in parts; neither the size of a part nor the interval between the appearance of successive parts is fixed, but each volume contains c. 280 pages.

Volume 15 (1960/61) and following, per volume $A £ 4$.13.6. Volume 1-7 out of print.

For subscriptions write to

\section{P. NOORDHOFF Ltd - PUBLISHERS}

Groningen, P. O. B. 39 - The Netherlands 
Books of outstanding importance

published by

\section{P. Noordhoff Ltd}

GRONINGEN - THE NETHERLANDS

Prof. Dr. V. Hlavaty, Indiana University, U.S.A.

\section{GEOMETRY OF EINSTEIN'S UNIFIED}

FIELD THEORY

Providing a detailed geometrical background for physical applications of this theory.

1958 XXXII +341 pp.

Cloth bound $\$ 9.75$

\section{DIFFERENTIAL LINE GEOMETRY}

Translation based on the German text by Prof. H. Levy. - An attempt to discuss line space with the help of the well-known projection of this space on a quadric in five-dimensional projective space.

$1953482 \mathrm{pp}$.

Cloth bound $\$ 6.70$

N. I. Muskhelishvili, Inst. of Math., Tiftis, U.S.S.R.

\section{SINGULAR INTEGRAL EQUATIONS}

Boundary problems of function theory and their application to mathematical physics.

Translated from the 2nd Russian ed. (1946).

Edited by J. R. M. Radok.

1953447 pp.

Cloth $\$ 7.60$

\section{SOME BASIC PROBLEMS OF THE MATHEMATICAL}

\section{THEORY OF ELASTICITY}

Fundamental Equations, Plane theory of Elasticity, Torsion and Bending.

Translated from the Russian by J. R. M. Radok.

1953 XXXII +704 pp.

Cloth $\$ 10.25$

Order through your local bookseller or direct from

P. Noordhoff Ltd., P. O. B. 39, Groningen, The Netherlands

Payment in the local currency is accepted. 